\title{
Evaluation of the Effects of Fasting On Fertility in Adult Male Wistar Rats
}

\author{
Omolaso ${ }^{1}$ B.O., Akanbi $^{2}$ C.O., Akintayo ${ }^{3}$ C.O., Oluwole ${ }^{4}$ F.S. \\ ${ }^{1,2,3}$ Department of Physiology, Bingham University, New Karu,Nasarawa State Nigeria \\ ${ }^{4}$ Department of Physiology, University of Ibadan,Ibadan,Nigeria
}

\begin{abstract}
This study was aimed at investigating the effect of different models of fasting on fertility of adult male wistar rats. 15 adult male rats were randomly divided into 3 groups. The rats in group 1(control) were fed ad libitum while rats in groups 2 and 3 were fasted 12hours and 24hours respectfully and fed withinl hour for 65 days. Fasting caused alteration in body and organ weights, food consumption, sperm motility, viability, volume and count, and reproductive hormones, LH, FSH and T. In the fasted rats, body weight increased progressively during the period of experiment by increased food consumption but the testes weight decreased significantly. Fasting blood sugar increased progressively as compared with the control group but within normal ranges for rats. There was no significant $(p>0.05)$ difference in the mean value of sperm volume of rats in the control and fasted groups. The degree of sperm motility was lowered but not significant ( $p>0.05)$.Sperm count was significantly $(p<0.05)$ lowered in the fasted animals compared to animals in control group indicating a drop in cellular turnover as a result of inhibition of spermatogenesis or cellular regression after fasting.

Serum LH and FSH were reduced significantly $(p<0.05)$. T concentration was also reduced but not significantly $(p>0.05)$. The significant reduction in LH and FSH might have accounted for the observed reduction in sperm counts in the fasted animals used for this study.
\end{abstract}

Key words: Fertility, Fasting and Sperm

\section{Introduction}

Fasting is defined as a partial or total abstention from all foods, or a select abstention from prohibited foods. As a potential non-pharmacological intervention for improving health and increasing longevity, fasting has been the subject of numerous scientific investigations.

Religious fasting is done in different teachings worldwide. Nigeria is known to be among the world most religious country of which fasting has become an integral part of the People . Christians fast for 24hrs daily for 40days while Muslims fast for $12 \mathrm{hrs}$ daily for 40days annualy for spiritual uplifment and an appeal to God to solve problems. The lack of calories consumed during fasting has dramatic effects on the body's systems. Because of the lack of glucose consumed, the liver converts glycogen stores into glucose and energy. Food supply has been considered to be one of the most important environmental variables controlling reproduction in animals. It has long been known that starvation adversely affect reproductive functions Rodjmark, (1987).Cameron et al, (1991). The hormones regulating reproduction and growth, especially those of hypothalamic-pituitary-gonadal axis are severely altered (Steiner et al, 2003)

The aim of this study is to evaluate the effect of (24hrs) and (12hrs) models of fasting on fertility in experimental animals

\section{Materials And Methods}

Healthy15adult male albino rats, weighing between(150-200) were housed in a well ventilated animal house at Bingham University Basic Health Sciences. Animals were allowed to acclimatize for seven days.

Rats were maintained under Controlled temperature of 28-30degree centigrade with natural Photoperiod (about 12 hours light and 12 hours darkness. Animals were divided into three groups of five rats each: GROUP 1serves as the control, received food and water for 65days. GROUP 2 were fasted 12hours daily(Muslim model) for 65 days while GROUP 3 were fasted 24hours dialy (Christian model) for 65 days. Groups 2 and 3 were fasted for one spermatogenetic cycle which requires 53 to 60 days out of which spermatozoa spend the last (6-7 days) in the final transit through epididymies (Wang et al ,2000). The amount of food introduced were weighed before and the amount left over after feed also weighed with electronic balance and subtracted from the the amount introduced to get the amount eaten by the fasted groups and recorded.

At 24 hours after the last feed, animals were weighed and sacrificed by cervical dislocation. Blood was collected through anterior canthes of the eyes using non heparinized capillary tubes for serum studies. 


\section{Results}

All animals were weighed every week with electronic balance. Initial and final weights of the animals were recorded. At the end of the treatment period, the animals were sacrificed 24hours after the last feed. The testes were removed and weighed immediately with an electronic weighing balance. At the end of every week, blood to measure glycemia was collected from the caudal vein using glucometer with test strips.

Whole blood was collected through anterior canthes of the eyes using non heparinized capillary tubes for serum studies. The blood samples were spun at $2500 \mathrm{rpm}$ for 10 minutes using a centrifuge,serum samples were assayed for luteinizing hormone(LH) using Microplate Immunoenzymometric assay(IEMA/ELISA) and testosterone(T) using an enzyme immunoassay (EIA)technique.

To determine sperm motility and sperm count, $100 \mathrm{mg}$ of caudal epididymies was minced in $2 \mathrm{mls}$ of physiological saline. One drop of evenly mixed sample was supplied to hemocytometer using the improved Neubauer's (Deep

1/110mm.LABART ,Germany) counting Chamber as described by Pant and Srivastava(2003).

Live /dead ratio was determined by using $1 \%$ Eosin and 5\% Nitrosin in 3\% sodium nitrate dehydrate solution according to the method described by Wells and Awa (1970).

Volume and the colour were determined by reading out the volume in a calibrated measuring cylinder while the colour was determined by visual assessment.

STATISTICAL ANALYSIS: All values body/organ weights, biochemical estimation were expressed as mean value \pm SEM.

The treatment groups were compared with the control group using student's $t$ test. $P$ value of $\leq 0.05$ was considered statistically significant.

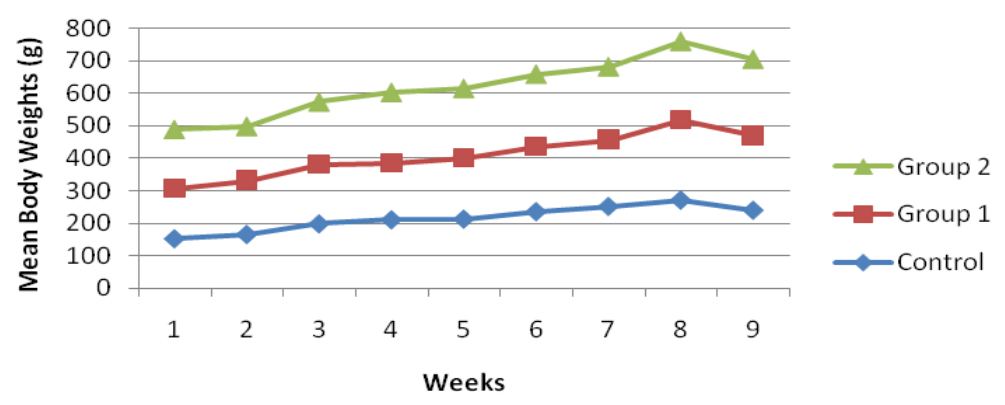

Fig 1 : EFFECTS OF FASTING ON BODY WEIGHT

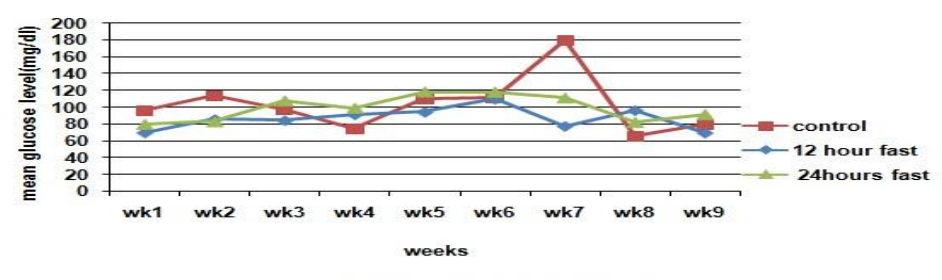

fig 2: EFFECT OF FASTING ON BLOOD GLUCOSE

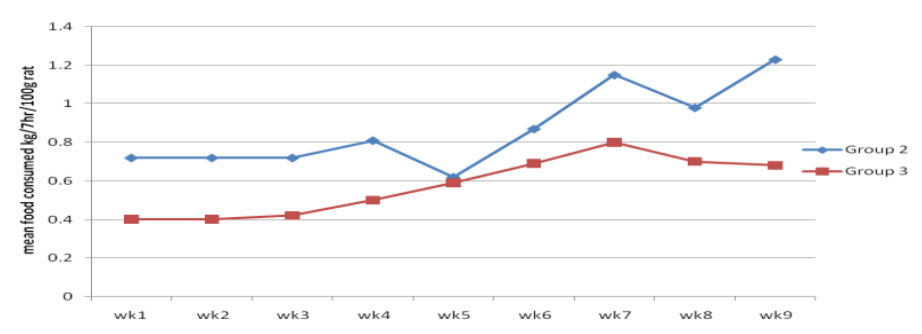

FIG 3: EFFECT OF FASTING ON FOOD CONSUMPTION AS AN INDEX OF APPETITE 
Evaluation Of The Effects Of Fasting On Fertility In Adult Male Wistar Rats

Table 1: BODY AND ORGAN WEIGHT CHANGES OF CONTROL AND FASTED RATS

\begin{tabular}{|l|l|l|l|}
\hline Groups & $\begin{array}{l}\text { Mean Initial Body } \\
\text { Weight }(\mathrm{g})\end{array}$ & $\begin{array}{l}\text { Mean Final Body } \\
\text { Weight(g) }\end{array}$ & $\begin{array}{l}\text { Mean } \\
\text { Weight }(\mathrm{g})\end{array}$ \\
\hline 1(control) & $135 \pm 4.59$ & $240.14 \pm 7.80$ & $2.58 \pm 0.24$ \\
\hline 2(fasted-12hrs) & $156.4 \pm 3.97$ & $229.4 \pm 5.44$ & $2.36 \pm 0.06^{*}$ \\
\hline 3(fasted-24hrs) & $215.8+3.80$ & $235.6+15.84$ & $2.34+0.02^{*}$ \\
\hline
\end{tabular}

$*(\mathrm{P}(<0.05)$ significantly different from the control

Table 2: EFFECT OF FASTING ON SPERM PARAMETER

\begin{tabular}{|l|l|l|l|l|}
\hline Groups & Motility (\%) & Live/Dead(\%) & Volume (cm $\underline{3})$ & Count (\%) \\
\hline 1 (control) & $90 \pm 2.74$ & $98 \pm 0.001$ & $5.2 \pm 0.02$ & $163.6 \pm 16.19$ \\
\hline 2 & $84 \pm 2.45$ & $95.2 \pm 1.46$ & $5.18 \pm 0.02$ & $106.6 \pm 8.22^{*}$ \\
& & & & \\
\hline 3 & $87 \pm 3.00$ & $96.2 \pm 0.73$ & $5.18 \pm 0.02$ & $109.2 \pm 7.57^{*}$ \\
\hline
\end{tabular}

Table 3: EFFECT OF FASTING ON HORMONES OF REPRODUCTION

\begin{tabular}{|l|l|l|l|}
\hline SERUM & FED RATS & $\begin{array}{l}\text { FASTED } \\
\text { RATS(12hrs })\end{array}$ & $\begin{array}{l}\text { FASTED } \\
\text { RATS(24hrs) }\end{array}$ \\
\hline LH mIU/ml & $35.8 \pm 8.00$ & $18.3 \pm 9.00^{*}$ & $16.4 \pm 6.00^{*}$ \\
\hline FSH mIU/ml & $19.4 \pm 1.03$ & $3.04 \pm 1.06^{*}$ & $3.14 \pm 0.98^{*}$ \\
\hline T ng/ml & $6.94 \pm 0.32$ & $3.78 \pm 0.47$ & $5.02 \pm 1.01$ \\
\hline
\end{tabular}

Values are means \pm SEM, LH, Luteinizing Hormone; FSH Follicle Stimulating Hormone; T,testosterone. Significant difference $*(\mathrm{p}<0.05)$

\section{DISCUSSIONS}

The present result shows a significant increase in body weight of the fasted rats when compared with the fed rats (Fig 1). Previous works reported a decrease in body weight during fasting. (Athar et al,1984;Hussein et al,(1987).In contrast, a study reported weight gain (Frost and Pirani, 1997)

Prolong fasting has been known to result in adaptive mechanisms for body weight maintenance.El-Ati $e t a l$, (1995).

Also, the liver has been known to have priority only when the nutritional supply is not enough to furnish the metabolic energy for tissues and organs Porter et al, (2004).

The observed progressive increase in mean food consumption with the period of fasting in the fasted rats indicates an adequate nutritional status that will not need the liver mobilize the adipose tissues. There was however, a drop in testicular weight in the fasted rats used for this study despite increase in body weight (Table $1)$.

The mean blood glucose increased progressively throughout the period of fasting as compared to controlled group (fed rats) (Fig 2) but still within normal range of 50 to $135 \mathrm{mg} / \mathrm{dL}$ in rats. This is supported by several a study in which food restricted rats showed adaptation for glycemia maintenance (Batista et al,(2000) The Sperm motility of rats in the fasted group was decreased but not significant ( $p>0.05)$. The inability of fasting to decrease sperm motility is explained by maintenance of glucose level within normal range throughout the 65 days of fasting in the two groups of animals used in this study. Sperm motility solely depends on blood glucose. The sperm viability of the fasted groups show no significant deviation $(p \geq 0.05)$ from what was obtained in the control group and the sperm cells ratio were within the same range as those of the control rats which shows that fasting did not affect the live ability of spermatozoa However, the mean sperm count was 
significantly reduced $(\mathrm{p}<0.05)$ in both $12 \mathrm{hrs}$ and $24 \mathrm{hrs}$ fasted rats indicating a drop in cellular turnover as a result of inhibition of spermatogenesis or cellular regression after fasting. The reduction in the sperm count explains the observed decrease in testicular organ weight, which is an indication that fasting reduced or inhibits spermatogenesis.

The Serum LH, FSH levels of fasted rats were significantly $(\mathrm{p}<0.05)$ decreased when compared with values obtained for control group (Table 3)

This result is in consistent with a study reported by Gonzale, et al,(2004.) where fasting was strongly demonstrated to inhibit gonadotropins.

It has long been known that starvation adversely affect reproduction function Rodjmark, (1987); Cameron et al, (1991. Food deprivation for 12 and 24hrs per day for a total number of 65 days in the two groups of animal used for this study might have had an inhibitory effect on both the secretion and the release of LH and FSH.

The serum $\mathrm{T}$ concentrations were lowered in fasted rats, although not significant. Based on this result, one could speculate that the slight reduction in serum $\mathrm{T}$ levels of fasted rats could be accounted for mainly due to decreased serum LH concentrations.

LH and FSH are intermediates in the hormonal pathways responsible for testosterone and sperm production. FSH stimulates the production of sperm production in the testicles while LH stimulates the production of testosterone in the leydigs cells. Testostrone in turns stimulate the development of immature sperm cells into mature sperm cells. Badger et al, (1985)

The significant reduction in LH and FSH might have accounted for the observed reduction in sperm counts in the fasted animals used for this study.

References

[1.] Athar,S. and M. Habib.Management of stable 2 diabetes mellitus NIDDM during Islamic fasting in Ramadan. First International congree on Health and Ramadan, 1994 19-22, Casablanca, Morocco.

[2.] Badger,T.m.Loughlin, J.S.and Naddaff, P.GThe luteinizing hormone desensitized rat pituitary:luteinizing hormone responsivenes s

[3.] LGRH in vitro.112, . 1985 .793-799.

[4.] Batista, M.R., Curi, R., Lima, F.B., Lopes, G., Bazotte R.B. Effect of a meal feeding schedule on hepatic glycogen synthesis and gluconeogenesis in rats. J. Biomed. Sci. 8, 2001, 256

[5.] Cameron,J.L.and Nosbisch,C .Suppression of pulsatile lutenizing hormone and testosterone secretion during short term food restriction in the adult male rhesus monkey (macaca mulatta). Endocrinology. 128: 1991,1532-1540.

[6.] El-Ati, J., C.Beji and Danguir. Increased fat oxidation during ramandan fasting in healthly women: An adaptive mechanism for body-weight maintenance. Am.J.Clin. Nutr., 62: 1995,302-307

[7.] Frost, G and S. Pirani() Meal frequency and nutritional intake during Ramadan: A pilot study. Human nutrition:Applied Nutr., 41,1997:47-50

[8.] Gonzales C, Voirol MJ, Giacomini M, Gaillard RC, Pedrazzini T, and Pralong FPThe neuropeptide Y Y1 receptor mediates NPYinduced inhibition of the gonadotrope axis under poor metabolic conditions. FASEB J 18: 2004, 137-139.

[9.] Hussein, R., M. T. Duncan and S.L. ChangEffects of fasting in Ramadan on tropical Moslems.Br. J.Nutr., 58:41-48

[10.] Neurosci Biobehav Rev 16: 1987,235-272.

[11.] Pant N, Srivastava SP. Testicular and spermatotoxic effect of quinaphos in rats. J. Appl. Toxicol. 23: 2003, 271-274.

[12.] Porter, M.H., Fine J.B., Cutchins, A.G., Bai, Y., Digirolamo, M. Sexual dimorphism in the response of adipose mass and cellularity to graded caloric restriction. Obes. Res. 12, 2004,131

[13.] Rodjmark S: Increased gonadotropin responsiveness to gonadotropin-releasing hormone during fasting in normal subjects. Metabolism 36, 1987 21,. 82.

[14.] Steiner J, LaPaglia N, Kirsteins L, Emanuele M, Emanuele N The response of the hypothalamic-pituitary-gonadal axis to fasting is modulated by leptin. Endocr Res. May; 29(2) 2003:107-17

[15.] Wells M.E, Awa O.A New technique for assessing acrosomal characteristics of spermatozoa. J. Diary Sci. 53: $1970,227$. 